rapid discontinuation elevating the blood pressure by withdrawal of the alpha blocking effect. Although the manufacturers state that this effect was not observed in clinical trials and would be unlikely on theoretical grounds as risperidone has a relatively long half-life ( 24 hours), it is to the best of our knowledge the first report of a hypertensive crisis occurring on risperidone withdrawal.

We thank Professor Malcolm Lader of the Institute of Psychiatry and Dr Anthony S. David of the Maudsley Hospital for their advice and comments.

Goodman, L. S. \& Gilman, A. (1985) The Pharmacological Basis of Therapeutics. 7th edition. Collier Macmillan.

Christopher G. KRASUCKI and James A. C. MACKEITH, Maudsley Hospital, Denmark Hill, London SE5 8AZ

\section{Problems with advocacy}

Sir: I would like to raise some potential problems with advocacy for clients with mental illness and learning disability.

$W$ is a patient with borderline intelligence and suffers from depression. He is physically fit although he has suffered from deep venous thrombosis and is treated with anticoagulants. He has been preoccupied with using a zimmer frame for about two years and which he has never needed. The staff strongly advised him and his family that he does not need it. His advocate was not happy about that and his premise was "it is his choice. What is wrong with having it". When the depression lifted the patient stopped requesting the zimmer frame.

$M$ has a moderate degree of learning disability and a psychopathic personality. In recent months he has been involved in assaultative behaviour including against an elderly person and a female doctor. An urgent MDT meeting was arranged in the presence of the approved social worker (ASW) and a section 3 order agreed in order to protect him and others and all agreed that this was the right thing to do. His advocate disagreed and said he would not allow it to happen. The ASW said she would not be influenced by the advocate's attitude but a few days later she apparently found that it was not necessary to put him on a section. A few weeks later $M$ told a senior staff member that he wanted to have sex with another person who could not give consent. When told he could not and should not he became aggressive and threatening. Days later he was approaching young teenagers. He also pretends to be a policeman and has been found directing traffic and asking for fines from drivers parking on yellow lines.

If $I$, as the responsible medical officer (RMO), fail to give appropriate, or give inappropriate, treatment I can be sued. What is the position if an untoward event happens to a patient or a third party as the result of obstruction or interference by a patient's advocate? I have also had experience of advocates acquiring confidential information about patients without permission from the RMO. It is worrying when one hears service managers insisting that everything done to a patient (client) should be discussed and preferably agreed by the advocate. Perhaps the College could advise on the best way forward. I would also like to hear about the experience and opinion of other colleagues.

Emad YousIF, New Possibilities NHS Trust, New Possibilities House, Turner Village, Turner Road, Colchester, Essex CO4 5JP

\section{Offensive or stigmatising labelling}

Sir: Our group has met to discuss ways of dealing with the problem of offensive or stigmatising labelling. The candidate for the most distressing and unacceptable term was, not surprisingly, 'schizophrenia' (even more so to be referred to as a 'schizophrenic' although people are becoming more educated about its mis-use).

We would like to ask for comments and suggestions from psychiatrists and others who read the Psychiatric Bulletin if they would be kind enough to write to:

Sue Stevens, Unit 5, Coopers Yard, Curran Street, Cardiff, South Glamorgan

\section{Improving initial attendance to a child and family psychiatric clinic: Austra- lian experience}

Sir: I thought it would be useful to look at the Australian scene and therefore surveyed the referrals made to my team over one year. I work as a team leader of the South West Outpatient Team at the Royal Children's Hospital, Melbourne offering a service to a 